\title{
CORRECTION
}

View Article Online

View Journal I View Issue

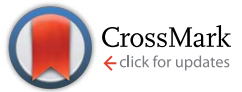

Cite this: RSC Adv., 2015, 5, 96870

\section{Correction: 3-Hydroxypropionaldehyde (3-HPA) quantification by HPLC using a synthetic acrolein- free 3-hydroxypropionaldehyde system as analytical standard}

\author{
G. Burgé, ${ }^{a b c}$ A. L. Flourat, ${ }^{\text {ade }}$ B. Pollet, ${ }^{b c}$ H. E. Spinnler ${ }^{\text {bc }}$ and F. Allais ${ }^{\star a b c}$ \\ DOI: $10.1039 / c 5 r a 90099 a$ \\ Correction for '3-Hydroxypropionaldehyde (3-HPA) quantification by HPLC using a synthetic acrolein-free \\ 3-hydroxypropionaldehyde system as analytical standard' by G. Burgé et al., RSC Adv., 2015, 5, 92619- \\ www.rsc.org/advances \\ 92627.
}

The authors regret that the image provided for Fig. 7 in the original article does not match the caption provided. The figure is presented below with an amended image.
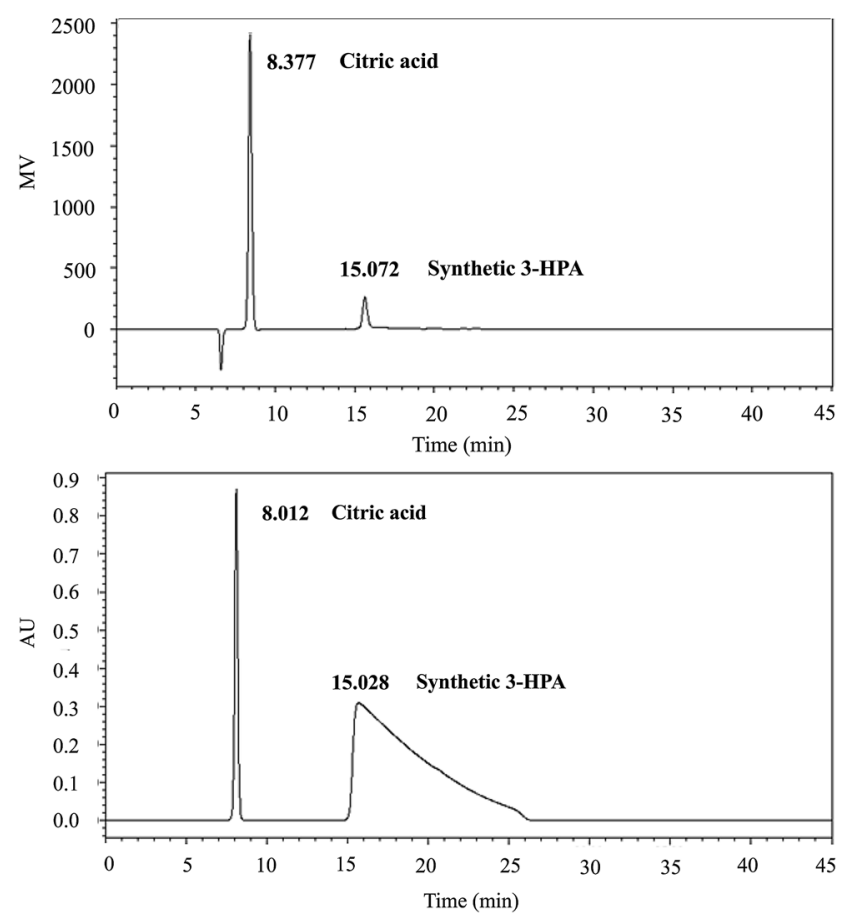

Fig. 7 Analysis of 3-HPA by HPLC (distilled water supplemented with $4 \mathrm{~g} \mathrm{~L}^{-1}$ of synthetic 3-HPA system). Chromatogram obtained by (Top) Refractive Index detection and (Bottom) UV detection at $210 \mathrm{~nm}$. Citric acid solution ( $C=5 \mathrm{mM}$ ) was used as internal standard and added at $50 \%$ $(\mathrm{v} / \mathrm{v})$ to the sample before HPLC analysis.

The Royal Society of Chemistry apologises for these errors and any consequent inconvenience to authors and readers.

${ }^{a}$ Chaire Agro-Biotechnologies Industrielles (ABI), AgroParisTech, F-51100 Reims, France. E-mail: florent.allais@agroparistech.fr; Tel: +33326364368 ${ }^{b}$ AgroParisTech, UMR 782 Génie et Microbiologie des Procédés Alimentaires (GMPA), F-78850 Thiverval-Grignon, France 'INRA, UMR 782 Génie et Microbiologie des Procédés Alimentaires (GMPA), F-78850 Thiverval-Grignon, France ${ }^{d}$ AgroParisTech, Institut Jean-Pierre Bourgin (IJPB), F-78026 Versailles Cedex, France ${ }^{e} I N R A$, Institut Jean-Pierre Bourgin (IJPB), F-78026 Versailles Cedex, France 